\title{
LEXICOGRAFIA E GEOLINGUÍSTICA: UM PEQUENO GLOSSÁRIO DE ITENS LEXICAIS RETIRADOS DE ATLAS LINGUÍSTICOS PERNAMBUCANOS
}

\section{LEXICOGRAPHY AND GEOLINGUISTICS: A SMALL GLOSSARY OF LEXICAL ITEMS PICKED UP FROM PERNAMBUCO LINGUISTIC ATLASES}

\author{
Edmilson José de Sá ${ }^{1}$ \\ Centro de Ensino Superior de Arcoverde (CESA)
}

\begin{abstract}
RESUMO
Este artigo estabelece uma conexão entre a lexicografia, ciência responsável pela construção de glossários e dicionários, e a geolinguística, método em que as variantes linguísticas são descritas numa perspectiva espacial através de mapas das comunidades investigadas. Para tanto, fundamenta-se nas perspectivas teóricas defendidas por Casares (1992), Biderman (2001), Borba (2003), Salvador (1980) e Alvar (1982) e na metodologia para construção de um glossário proposta por Faulstich (1995), Zanette (2001) e Barbosa (2001). De posse desse conhecimento, alguns itens lexicais coletados nos inquéritos realizados para os quatro atlas linguísticos pernambucanos serão organizados num pequeno glossário de modo a possibilitar o reconhecimento de possíveis marcas dialetais do falar pernambucano e compreender, quando possível, questões relacionadas à etimologia dessas marcas à luz de referências lexicográficas.
\end{abstract}

PALAVRAS-CHAVE: Lexicografia; Geolinguística; Atlas linguísticos pernambucanos; Glossário.

\begin{abstract}
This article establishes a connection between Lexicography, science responsible for construction of glossaries and dictionaries, and the Geolinguistics, method in which the linguistic variants are described in a spatial perspective through maps of the investigated communities. So, it is based on the theoretical perspectives defended by Casares (1992), Biderman (2001), Borba (2003) Salvador (1980) e Alvar (1982) and the methodology for building a glossary proposed by Faulstich (1995), Zanette (2001) and Barbosa (2001). In possession of this knowledge, a few lexical items collected in surveys conducted for the four Pernambuco Linguistic Atlases will be organized in a small glossary in order to facilitate the recognition of possible Pernambuco speech dialect and to understand, as possible, questions concerned to the etymology of theses marks according to lexicographical references.
\end{abstract}

KEYWORDS: Lexicography; Geolinguistics; Pernambuco Linguistic Atlas; Glossary.

\section{INTRODUÇÃO}

Partindo do princípio que o léxico de uma língua se constitui do acervo vocabular de um grupo sociolinguístico-cultural como apregoam Oliveira e Isquerdo (2001, p. 9), três ramos de investigação se ocupam de estudá-lo com maior profundidade. A lexicologia, que se ocupa das

\footnotetext{
${ }^{1}$ Doutor em Letras - Linguagem e Cultura, pela Universidade Federal da Paraíba e Pós-Doutor em Letras - Análise Descrição e Documentação das Línguas Naturais, pela Universidade Federal do Pará. Professor de Língua e Literatura no Centro de Ensino Superior de Arcoverde e Professor Colaborador do Mestrado PROFLETRAS Universidade de Pernambuco - Campus Garanhuns. Contato: edjm70@gmail.com
} 
questões teóricas acerca da estrutura do léxico e de suas variações flexionais; a lexicografia, que consiste na elaboração de dicionários, vocabulários e glossários; e a terminologia, que busca reunir termos especializados próprios de uma ciência, arte, técnica ou profissão.

Considerando o propósito de construção de um glossário com verbetes selecionados a partir das cartas dos atlas já construídos sobre o falar de Pernambuco, convém fazer uma breve abordagem teórico-metodológica sobre a lexicografia e a relação que ela pode concretizar com a Geolinguística, método usado para a construção dos atlas, bem como um panorama descritivo das produções lexicográficas já existentes nos atlas linguísticos regionais do Brasil.

\section{Uma visão panorâmica da lexicografia}

A lexicografia e a lexicologia têm um objeto comum de estudo para a descrição do vocabulário de uma língua. A diferença essencial entre elas se encontra no grau de sistematização e completude. O primeiro aspecto destina-se à sistematização, revelando características de palavras. Já o segundo busca a descrição semântica formal e funcional de todas as palavras individuais. Em termos mais específicos, Casares (1992, p. 11) diferencia as duas ciências da seguinte maneira:

Da mesma forma que podemos distinguir uma ciência da gramática e uma arte da gramática, podemos distinguir duas faculdades, que têm por objeto comum a origem, a forma e o significado das palavras: lexicologia, que estuda esses temas do ponto de vista geral e científico, e a lexicografia, cujo papel, principalmente utilitário, é justamente definido em nosso léxico como 'a arte de compor dicionários' (tradução nossa). ${ }^{2}$

Considerando um dos objetivos deste trabalho de construir um glossário do falar pernambucano, dar-se-á ênfase à lexicografia, que pode ser vista sob duas perspectivas distintas, conforme encontrado em Borba (2003, p. 15):

a) Técnica de montagem de dicionários, ocupando-se de critérios para seleção de nomenclaturas ou conjunto de entradas, de sistemas definidores, estrutura de verbetes, critérios para remissões e registro de variantes;

b) Numa visão mais teórica, consiste de estabelecer um conjunto de princípios que permitem descrever o léxico - total ou parcial - de uma língua, desenvolvendo uma metalinguagem para manipular e apresentar as informações pertinentes.

A análise lexical é feita a partir de algumas distinções. A priori, convém observar a preferência em usar 'lexia' ou 'lexema' em lugar de 'palavra' ou 'vocábulo', por aqueles se referirem diretamente à escrita e ao significado, respectivamente, e estes terem relação ao sistema, à língua em si como entidade abstrata e supra-individual, no caso da primeira denominação ou à fala, ao discurso, no caso do segundo conceito, como sugere Borba (2003, p. 19).

Concernente à estrutura mórfica do léxico, costumam ser aplicados dois níveis, o das lexias simples, com apenas um elemento livre, como homem, casa, e complexas, quando combinam duas lexias de mais de uma forma livre, como mercado-negro, porta-bandeira.

Outro ponto a considerar é a questão da composição e da derivação das lexias. Enquanto o primeiro aspecto objetiva associar as formas livres, como passa + tempo $\rightarrow$ passatempo, o segundo associa uma forma livre a uma ou mais formas presas, como im + possível $\rightarrow$ impossível.

${ }^{2}$ De igual manera que distinguimos una ciencia de la gramática y una arte de la gramática, podemos distinguir dos facultades, que tienen por objeto común el origen, la forma y el significado de las palabras: la lexicología, que estudia estas materias desde un punto de vista general y científico, y la lexicografía, cuyo cometido, principalmente utilitario, se define acertadamente en nuestro léxico como el 'arte de componer diccionarios'. 
De posse de sua composição ou derivação, a lexia pode ser agrupada a classes, conforme os traços que compartilham. São, então, formados dois conjuntos, os nomes (substantivos) e os verbos. Em seguida, surgem os adjetivos associados aos nomes e os advérbios associados aos verbos.

O léxico pode ser facilmente ampliado não apenas pelos mecanismos de estruturação mórfica, mas por processos enriquecedores, destacados por Borba (2003, p. 119) quais sejam: o neologismo e o empréstimo.

Para o autor, a criação neológica ocorre seguindo dois parâmetros, a recontextualização de palavras em circulação e consequente aparecimento de nova acepção, como também a incorporação de novos itens ao léxico geral. No primeiro caso, contudo, tal criação é ocasionada pela interferência social da língua, enquanto o segundo caso pode ser realizado pela simples aplicação da regra morfológica ou empréstimos de línguas com que mantém contato.

Não é possível tratar de léxico sem adentrar na questão semântica, já que a circulação de lexias de uma língua se caracteriza tanto pela renominação, multiplicando os itens léxicos, como pela polissemia, multiplicando as acepções. Além disso, vale a pena lembrar a dicotomia sinonímia / paronimia, que tem na primeira a equivalência de significado e na segunda, a semelhança fônica entre lexias.

Valendo-se da ideia de Biderman (2001, p. 13) de que "o léxico de uma língua natural constitui uma forma de registrar o conhecimento do universo", foi possível, neste subtópico, visualizar um pouco do propósito da lexicografia. Cabe, agora, identificar quais os mecanismos mais concretos de registrar esse conhecimento e como isso pode ser realizado.

\section{Entendendo as nuances de um glossário}

O conceito de glossário também suscita alguns posicionamentos que merecem reflexão.

Horrozco (1611, p. 33), por exemplo, ao se remeter à etimologia grega 'glossa', se aproxima da definição que justifica a construção do glossário proposto neste artigo. Para ele:

Significa língua, mas comumente se toma por anotações e comentários que os textos declaram, ou qualquer outro escrito. Glosar alguma coisa escrita ou dita é interpretá-la. Glosar as palavras vulgarmente é lhes dar outro sentido do que pensa ou ao contrário do que se pretendia (tradução nossa). ${ }^{3}$

Em outras palavras, Boutin-Quesnel et al. (1985, item 3.1.4) conceituam o glossário como um repertório que define ou explica os termos antigos, raros ou desconhecidos, enquanto Faulstich $(1995$, p. 6) refuta essa definição e oferece três opções numa perspectiva mais estrutural, disposta no quadro abaixo:

\section{Quadro 1: Definições de glossário}

a) Repertório que define termos de uma área científica ou técnica, dispostos em ordem alfabética, podendo apresentar ou não remissivas.

b) Repertório em que os termos, normalmente de uma área, são apresentados em ordem sistemática, acompanhados de informação gramatical, definição, remissivas podendo apresentar ou não contexto de ocorrência.

c) Repertório em que os termos são apresentados em ordem alfabética ou em ordem sistemática seguidos de informação gramatical e do contexto de ocorrência.

Fonte: Faulstich (1995)

\footnotetext{
3 Vale lengua, pero comúnmente se toma por las anotaciones, y comentos que declaran los textos, o otra cualquier escritura, Glosar alguna cosa escrita o dicha es interprétala. Glosar las palabras, vulgarmente es dátales otro sentido del que suena y a vez del que pretendió es que las dicho.
} 
Pela leitura de definições arroladas acima, parece que não há um consenso em relação a qual delas deve ser defendida ou recusada, uma vez tais conceitos se complementam, quer na questão dos dicionários, quer na questão dos glossários, daí o fato de tais conceitos serem registrados, na visão de grande parte dos estudiosos em lexicografia, terminologia ou terminografia, como sinônimos, cabendo, pois, a elaboração de critérios que delimitem o verdadeiro objetivo da produção lexicográfica. Para tanto, convém, a seguir, apresentar como se estrutura basicamente um glossário.

\section{A estrutura de um glossário}

Considerando o conceito de glossário de Faulstich (1995), o repertório costuma ter seus verbetes distribuídos em ordem alfabética, representando uma área técnica ou científica e contendo informações pertinentes à compreensão do significado, agrupadas em elementos gramaticais, variacionistas e especificamente lexicográficos, como os campos conceituais e as referências a possíveis dicionarizações, alterações semânticas ou mesmo acerca da entrada de um termo novo.

Para contemplar todos os aspectos supracitados, o glossário, assim como o dicionário, se estrutura a partir de dois níveis: a macroestrutura e a microestrutura. A primeira, conforme encontrado em Faulstich (op cit, p. 10) inclui os verbetes em ordem alfabética e outros aspectos da entrada, como a ordem relacionada à homonímia e à polissemia.

No caso do Houaiss (2009), por exemplo, a entrada é registrada como lexia simples ou composta por hífen, um elemento mórfico, uma locução ou redução. Os homônimos foram registrados de duas formas. Os homógrafos homófonos possuem um algarismo alceado à esquerda da unidade léxica. Já no caso dos homógrafos não homófonos, com até duas entradas, apenas o timbre aberto antecipa o fechado, não havendo, pois, nenhuma outra regra de diferenciação. Ultrapassando duas entradas, são construídos grupos heterônimos autônimos com uma numeração alceada própria. Os quadros 2 e 3 servem de parâmetro comparativo para a compreensão da microestrutura do referido dicionário.

Quadro 2: Entrada de verbete de homógrafos homófonos

Jaca. s.f. (1535) fruto da jaqueira, um sincarpo frequentemente enorme e pesado, geralmente cilíndrico ou subgloboso.

2Jaca. s.f. (1899) chefe superior de várias tribos africanas; régulo, soba

Fonte: Houaiss (2009)

Quadro 3: Entrada de verbete de homógrafos não homófonos

Bordo \ó \s.m. (sXIII) 1 MAR cada uma das duas partes simétricas em que se divide longitudinalmente o casco das embarcações.

Bordo \ô \s.m. (sXV) ANGIOS 1 design. comum às árvores e arbustos do gên. Acer, da fam. das aceráceas, esp. explorados e/ou cultivados pela madeira, ger. branca, leve e compacta, pela seiva açucarada, e como ornamentais

Fonte: Houaiss (2009)

A microestrutura, por outro lado, se refere ao programa de informações contidas nos verbetes sobre o termo - entrada, compondo-se de dados relativos à classe lexical / categoria gramatical, contextos de uso, sinônimos e outras informações, conforme o modelo escolhido para a obra.

Haensch et al. (1982) apresentam, ainda, diferenças ortográficas, cronológicas e geográficas, etimologia, níveis de estilo e conotações, atribuição a uma matéria ou especialidade, marcas registradas e denominações oficiais, ou seja, são as informações do verbete organizadas e estruturadas a depender do interesse do lexicógrafo. 
Um modelo de microestrutura proposto por Faulstich (1995, p. 10) pode ser contemplado no quadro 4 :

Quadro 4 : Modelo de microestrutura de produções lexicográficas

Verbete $=+$ entrada + categoria gramatical $( \pm$ substantivo, \pm sintagma terminológico, \pm verbo) \pm gênero \pm sinônimo \pm variantes \pm fonte \pm área \pm subárea \pm definição \pm fonte + contexto + fonte \pm remissivas \pm equivalentes \pm fontes.

$$
\text { Fonte: Faulstich (1995) }
$$

Via de regra, lexicógrafos também usam modelos mais resumidos, como o proposto por Zanette (2011, p. 350), que agrupa os enunciados em paradigmas, conforme proposto em Barbosa (2001, p. 39) e consta de notas linguísticas e enciclopédicas.

\section{Quadro 5: Modelo de microestrutura}

Verbete $=+$ entrada em português + paradigma informacional $(+$ categoria gramatical, + gênero + número); + forma equivalente em língua italiana; + paradigma definicional (definição redigida em língua portuguesa); + paradigma pragmático (abonação em língua portuguesa); +/- remissivas (para as formas sinonímicas e variantes preferenciais como siglas e acrônimos, além dos hiperônimos, hipônimos, co-hipônimos $\left.{ }^{4}\right) ;+/-$ notas de caráter linguístico e/ou enciclopédico

$$
\text { Fonte: Zanette (2011) }
$$

Considerando que os registros de variantes linguísticas do falar pernambucano foram compilados em atlas linguísticos, cujo arquétipo advém do método da Geolinguística, torna-se conveniente a elaboração de um glossário de itens lexicais no intuito de conhecer alguns termos que requerem especial atenção para a confirmação de variantes locais e regionais.

Por isso, pretende-se, a seguir, fazer uma reflexão sobre uma possível interface entre a Geolinguística e a criação de atlas linguísticos com a Lexicografia, responsável pelo registro lexical em dicionários ou glossários.

\section{Lexicografia e geolinguística}

A Geolinguística constitui um método de análise usado para estudos dialetais, aproveitando a Cartografia, na identificação de variantes diatópicas a partir da construção de atlas linguísticos. Porém, a leitura desses atlas nem sempre ocorre com facilidade, uma vez que eles:

[...] exigem agilidade de manusear e precisam ser consultados de pé em longas mesas limpas. Mas isso não impede o seu uso, porque se eles são construídos, sem pouco esforço, com mais trabalho e contrariedades do que seu uso agora requer, é para alguma coisa, eu digo. Eu acho que, talvez por causa das partes interessadas, nem os estudiosos acadêmicos, nem os estudantes de doutoramento inexperientes podem se dar ao luxo de ignorá-los, embora estes tenham mais facilidades de organizá-los do que aqueles. (SALVADOR, 1980, p. 56, tradução nossa) ${ }^{5}$

\footnotetext{
${ }^{4}$ Conforme encontrado em Houaiss (2009), trata-se de ou cada uma das unidades léxicas do mesmo nível cujo significado está incluso num hiperônimo, como, por exemplo, os verbetes cavalo, cão, gato em relação ao hiperônimo mamifero.

${ }^{5}[\ldots]$ requieren agilidad para su manejo y han de consultarse de pie, abiertos sobre largas mesas despejadas. Pero eso no exime de su utilización, porque si se han hecho, con no poco esfuerzo, con mayores ajetreos y sinsabores de los que su uso ahora requiere, es para algo, digo yo. Me parece — tal vez por ser parte interesada — que ni los doctos académicos ni los bisoños doctorandos se pueden permitir el lujo de ignorarlos, aunque a los segundos les pueda resultar más fácil moverlos que a los primeros.
} 
Nesse pensamento, Alvar (1982, p. 60) acredita que o estudo de cartas de um atlas linguístico possibilita uma análise da linguagem real, suscitando uma gama de análises distintas, inclusive sob a perspectiva lexicográfica, ratificando a ideia de Soriano (1932, p. 7) de que "a lexicografia, a fonética, a etimologia e a gramática histórica têm, na dialetologia, uma veia inesgotável para explorar" (tradução nossa). ${ }^{6}$

$\mathrm{Na}$ realidade, ao se deparar com ocorrências desconhecidas nos atlas linguísticos, costuma-se dirimir dúvidas sobre a pronúncia, a ortografia, e o uso da lexia pouco utilizada, incluindo abordagens etimológicas, que podem auxiliar na compreensão do significado dessa lexia.

É, pois, através da lexia (palavra) que o indivíduo participa dos feitos que caracterizam a vida: sua insegurança, sua evolução e sua complexidade e produções lexicográficas, como o dicionário oferece o adorno às palavras, mantendo-as imobilizadas e se perpetuando de geração em geração. Além disso, conforme apregoado por Oliveira (1999, p. 251),

[...] entre as informações comumente encontradas nos verbetes dos dicionários estão as que fazem referência as marcas de uso, procedimento classificatório por meio do qual se torna possível perceber a variação linguística, que se processa no eixo horizontal (regionalismos) e no vertical (registros).

Por esse motivo, alguns atlas linguísticos têm proporcionado algo além das notas visualizadas no verso das cartas. Trata-se da construção de glossários, pois, além de organizarem itens registrados segundo a frequência ou o desconhecimento do significado, possibilitam uma leitura mais aperfeiçoada de cada carta linguística.

Os glossários buscam, então, registrar o que Biderman (2001, p. 135) chama de 'regionalismo', pois ele representa "qualquer fato linguístico (palavra, expressão, ou seu sentido) próprio de uma ou de outra variedade regional do português do Brasil", distinguindo-se da norma padrão. Essa perspectiva contrastiva, segundo Isquerdo (2007, p. 200), também é usada como parâmetro para o conceito de 'brasileirismo', por delimitar a norma brasileira em relação à europeia.

Julga-se, então, conveniente agregar os registros lexicais encontrados nos atlas linguísticos à produção lexicográfica, na iminência de conseguir delinear marcas dialetais, retificar ou manter grafias e precisar a distribuição de sinônimos. Comunga-se, portanto, do que Zumbado e Dias (2002, p. 1219) afirmam:

Na lexicografia regional, o atlas tende a ser, por sua extensão e conteúdo, o repertório lexical mais amplo de que dispõe o dialetólogo e, portanto, fonte primária do vocabulário diferencial, que servirá como uma grande ajuda na criação de orações e suas variantes, as etimologias, significados e as marcas mais amplas.

\section{Uma descrição dos glossários nos atlas linguísticos brasileiros}

Os atlas linguísticos visam ao mapeamento de variações diatópicas, cujo registro se pauta no que o falante nativo de uma dada comunidade utiliza em sua comunidade em ambientes fonéticos, lexicais e morfossintáticos.

Concernente ao léxico, Vilela $(1994$, p. 216-217) o caracteriza como a totalidade das palavras de uma língua ou como o saber interiorizado, por parte dos falantes de uma comunidade linguística, acerca das propriedades lexicais das palavras (fonéticas, sintáticas e semânticas), ou

\footnotetext{
${ }^{6} \mathrm{La}$ lexicografía, la fonética, la etimología y la gramática histórica tienen en la dialectología un inagotable filón que explotar.
} 
seja, pode-se concordar com Carvalho (2009, p. 20) quando diz que ele 'faz parte do conjunto da língua, da mesma forma que o sistema fonológico, a flexão, a construção da frase e os processos de formação de palavras'.

É esse inventário de elementos que pode ser contemplado em itens lexicais registrados em variados documentos, dentre os quais os atlas linguísticos, em cujas cartas estão dispostas as variantes mais recorrentes no território pesquisado.

Porém, em alguns desses atlas também constam relações lexicais compiladas em glossários das mais variadas tipologias. Assim, pretende-se, aqui, fazer um recorte desses glossários já catalogados nos atlas regionais brasileiros.

No Esboço de um Atlas Linguístico de Minas Gerais (RIBEIRO et al., 1977) consta um glossário com 139 verbetes distribuídos entre lexias simples, compostas e complexas, sem registro de dicionarização semelhante ao sentido conferido nas cartas. As entradas são todas em caixa alta, seguidas da categoria gramatical e o registro da remissiva. A indicação da dicionarização é feita através de asteriscos. Com um asterisco eram registrados os verbetes com acepção diferente e com dois asteriscos constavam os verbetes não dicionarizados. O quadro 6 apresenta alguns dos itens do referido glossário:

Quadro 6: Exemplos de entradas do glossário do EALMG

ALÇAPÃO*, s.m.: burrica

ARCO-DO-SOL**, s.m.: arco-íris

BISCOITINHO-ASSADO**, s.m.: chicotinho-queimado

CARTOLA*, s.m.: papagaio (de papel)

ESTRELA-DO-NORTE*, s.f.: estrela-cadente

MUTUCA*, s.f.: (pular) carniça

SETA*, s.f. atiradeira

TRUBIDANGA**, s.f.: tromba d'água

Fonte: Ribeiro et al. (1977)

O Atlas Linguístico da Paraíba (ARAGÃO; MENEZES, 1984) apresenta, ao final de seu segundo volume, um glossário de 362 termos com a seguinte normatização:

a) Foram selecionados os termos de maior frequência do Estado, os dicionarizados com sentido diferente e os não-dicionarizados;

b) Cada termo possuiu sua transcrição fonética;

c) Não foram apresentadas definições dos termos, de modo a possibilitar o leitor ao termo básico, tema de cada carta;

d) Cada termo foi localizado a partir da carta em que foi registrada sua ocorrência, no intuito de fazer o leitor ter mais condições de compreender o campo semântico a que o referido termo se refere;

e) Não houve referência a termos dicionarizados com o mesmo significado do que fora apresentado nas cartas. Porém, ao ser constatado o significado diferente ou a nãodicionarização, o termo foi antecedido por um asterisco.

f) Cada entrada de expressões foi feita pela expressão completa e não apenas pela palavra-chave;

g) Além de dicionários de língua portuguesa, também foram consultados dicionários específicos do falar paraibano.

O quadro 7 exemplifica como foram registrados alguns dos verbetes do glossário do Atlas Linguístico da Paraíba. 
Quadro 7: Exemplos de registros de verbetes do Glossário do ALPA

Abafado R. [aba'fadu] Mormaço (carta $\left.n^{\circ} 028\right)$

*Água choca R. ['agwa'`oka] Barreiro (carta n’ 009)

*Bustiê R. [bufti'e] Sutiã (carta no 051)

*Cangalhudo R. [kãgaj'udu] Corno (carta no 091)

Cortiço R. [kuh'tisu] Colmeia (carta n $\left.{ }^{\circ} 121\right)$

Desinquieta R. [dizíki'cta] Trelosa (carta no 099)

Fona R. ['fõna] 1. Sovina (carta $\left.n^{\circ} 083\right) ; 2$. Bolinha de gude ( $\left.\operatorname{carta~}^{\circ}{ }^{\circ} 105\right)$

Fonte: Aragão e Menezes (1984)

Isquerdo (2007, p. 197) faz referência ao glossário do Atlas Linguístico do Paraná, que consta de 1.163 itens do léxico rural do Estado e, ainda, cita outros trabalhos de descrição lexical realizados por docentes sobre as ocorrências catalogadas no Atlas Prévio dos Falares Baianos (ROSSI et al, 1963) e no Atlas Linguístico de Sergipe (FERREIRA et al, 1987).

A quarta seção do Atlas Linguistico do Paraná II (ALTINO, 2007) apresenta uma relação de 935 verbetes que compreendem o universo vocabular dos falantes do Estado.

Para a apresentação dos verbetes, adotou-se a norma ortográfica padrão. Contudo, havendo uma variante dessa forma, foi adotado o critério da aproximação entre elas e o conceito trouxe a indicação, entre parênteses, da carta onde a variante foi registrada. Além disso, outros critérios normativos foram adotados, de modo a facilitar a catalogação e consequente leitura dos verbetes do glossário.

Já no Atlas Linguístico do Mato Grosso do Sul, organizado por Oliveira (2007), não se encontra uma referência direta a um glossário, mas a uma descrição lexical com 49 entradas e o glossário do Atlas Linguístico do Ceará (BESSA et al, 2010) apresentou os itens que constituem o universo dos informantes analfabetos. Para isso, as entradas foram inseridas em letras maiúsculas, seguidas da sua transcrição fonética. Em seguida, quando necessário, foi feita uma referência a indicação da carta através das siglas O.U (Ocorrências únicas) e O.R. (Outras realizações).

Cada entrada remeteu à pergunta do questionário aplicado e também apresentou a indicação da carta onde a ocorrência foi registrada. Além disso, também constam as indicações dos informantes analfabetos (INF.: Ø) e dos pontos de inquérito.

O quadro 8 apresenta um exemplo de como foi registrado verbete 'ovido':

Quadro 8: Exemplo de registro do verbete 'ovido' no Glossário do ALECE

OVIDO [o'gido], [o'vido], [o'vido] e [o'vido], s.m. PERGUNTA 078: A gente escuta o som ou uma voz com o... CARTAS 178. L079, 180.F101 e 184.F103. INF.: $\varnothing$. PONTOS: 58, 64, 66, 65, 20, 2, 22, 3, 7, 39, 25, 17, 8, 9, 12, 10, 15, 13, 24, 50, 49, 47, 51, $53,54,69,70,32,28,26,31,35,30,36,34,57,56,41,40,67,46,45,44,60,62,61$.

Fonte: Bessa et al. (2010)

\section{Glossário léxico-semântico de itens registrados nos atlas do falar pernambucano}

Para compreender um pouco melhor das marcas dialetais registradas em Pernambuco, serão utilizados os itens lexicais mais proeminentes dos atlas já concluídos, cuja descrição resumida vem em seguida:

Quadro 9: Configuração dos Atlas linguísticos pernambucanos

\begin{tabular}{|l|c|c|c|c|}
\hline Atlas & $\begin{array}{c}\text { Atlas Linguístico } \\
\text { da Mata-Sul de } \\
\text { Pernambuco } \\
\text { (ALMEIDA, 2009) }\end{array}$ & $\begin{array}{c}\text { Atlas } \\
\text { Linguístico de } \\
\text { Buíque } \\
\text { (FERREIRA, }\end{array}$ & $\begin{array}{c}\text { Esboço de um } \\
\text { atlas linguístico } \\
\text { rural de } \\
\text { Pernambuco } \\
\text { (SÁ; ANDRADE }\end{array}$ & $\begin{array}{c}\text { Atlas Linguístico } \\
\text { de Pernambuco } \\
\text { (SÁ, 2013) }\end{array}$ \\
\hline
\end{tabular}




\begin{tabular}{|c|c|c|c|c|}
\hline & & & NETO, 2013) & \\
\hline Informantes & $\begin{array}{l}18 \text { a } 30 \text { anos e de } 40 \\
\text { a } 65 \text { anos }\end{array}$ & $\begin{array}{l}18 \text { a } 30 \text { anos e de } \\
50 \text { a } 65 \text { anos }\end{array}$ & 12 a 22 anos & $\begin{array}{l}18 \text { a } 30 \text { anos e de } \\
50 \text { a } 65 \text { anos }\end{array}$ \\
\hline Localidades & $\begin{array}{lr}\text { Barreiros, } & \text { Belém de } \\
\text { Maria, } & \text { Palmares, } \\
\text { Ribeirão, } & \text { São } \\
\text { Benedito do Sul e } \\
\text { Sirinhaém }\end{array}$ & $\begin{array}{l}\text { Bairros de } \\
\text { Vila do Posto, } \\
\text { Frei Damião, } \\
\text { Centro, Bairro } \\
\text { Cruz de São } \\
\text { Benedito e São } \\
\text { José }\end{array}$ & $\begin{array}{l}\text { Sítios de } \\
\text { Arcoverde, } \\
\text { Alagoinha, Buíque, } \\
\text { Custódia, Caetés, } \\
\text { Ibimirim }\end{array}$ & $\begin{array}{l}\text { Afrânio; Petrolina; } \\
\text { Santa Maria da Boa } \\
\text { Vista; Ouricuri; } \\
\text { Salgueiro; Floresta; } \\
\text { Tacaratu; Serra } \\
\text { Talhada; Custódia; } \\
\text { São José do Egito; } \\
\text { Tupanatinga; } \\
\text { Arcoverde; Águas } \\
\text { Belas; Garanhuns; } \\
\text { São Bento do Una; } \\
\text { Taquaritinga do } \\
\text { Norte; Caruaru; } \\
\text { Palmares; Recife }\end{array}$ \\
\hline $\begin{array}{l}\text { Indicações } \\
\text { cartográficas }\end{array}$ & $\begin{array}{l}45 \text { cartas semântico- } \\
\text { lexicais }\end{array}$ & $\begin{array}{l}40 \quad \text { cartas } \\
\text { semântico- } \\
\text { lexicais }\end{array}$ & $\begin{array}{lr}40 & \text { cartas } \\
\text { semântico-lexicais }\end{array}$ & $\begin{array}{l}50 \text { cartas fonéticas, } \\
47 \text { semântico- } \\
\text { lexicais e e } 8 \\
\text { morfossintáticas }\end{array}$ \\
\hline
\end{tabular}

Fonte: o autor

Segundo critérios já existentes na construção de glossários, resolveu-se minimizar os dados por questões de espaço e seguir a estrutura em tela:

a) Entrada dos verbetes: através da indicação da classe de palavra, do gênero ou número, conforme registrado no inquérito

b) Indicação da carta lexical (CL)

c) Indicação do atlas onde foi registrado o item lexical (ALMASPE, ALiBUI, EALIRPE, ALiPE)

c) Indicação do conceito (CO)

d) Indicação de nota linguística a partir da etimologia do verbete, quando possível (NL)

e) Indicação de remissivas (VER)

f) Campo semântico atlas.

Seguem, então, um glossário com algumas marcas linguísticas encontradas nos quatro

Almocrevo: s.m.

CL 18 - ALiPE

Malas de couro presa às cangalhas dos cavalos ou atravessadas na sela, usadas para transportar objetos e mercadorias.

NL: Relativa ao almocreve, do árabe almukari (HOUAISS, 2009)

Ver: alforje

- Atividades agropastoris

\section{Aprisco s.m.}

CL 12 = EALIRPE

Local onde as cabras ficam alojadas

N.L. Redução de apriscar, do latim N.L. Do latim bacca, 'fruto miúdo', 'bola'.
Apocã: s.m.

CL 02 - ALMASPE

Fruta menor que a laranja que deixa cheiro na mão

N.L. Do japonês, ponkan. (HOUAISS, 2009)

Ver: tangerina, mexerica.

- Atividades agropastoris

Baga s.m.

CL 36 - ALiPE

Resto de cigarro que se joga fora 
*appressicáre de ad- + *pressicáre $<$ (HOUAISS, 2009)

pressus - particípio passado de premère + - - Convívio e comportamento social

icáre (HOUAISS, 2009)

Ver: curral, cercado, chiqueiro

- Atividades agropastoris

Baixio s.m.

CL5 - EALIRPE

Lugar onde há muitas fruteiras

N.L. do latim bassus + io (HOUAISS, 2009)

Ver: plantio, pomar

-Atividades agropastoris.

\section{Banguêt 2 s.m.}

CL 41 - ALiPE

Tábua apoiada ao meio em cujas pontas sentam duas crianças, sendo que quando uma sobe, a outra desce.

Ver: gangorra, canoa. balanço, escorrego

- Jogos e brincadeiras infantis.

\section{Cangapé s.m.}

CL 38 - ALiPE

N.L. Tanto Ferreira (1986, p. 335) quanto Houaiss (2009) apontam a origem para cambapé, influenciada por canga. Cambapé é uma lexia formada pelo verbo cambar + pé e cambar advém do latim cambiare, 'trocar'. Ver cambumba.

- Jogos e brincadeiras infantis.
Banguê, 1 s.m.

CL 02 - ALiPE

Pedaço de pau ou tábua usado sobre um riacho para atravessar.

N.L. Segundo encontrado em Lopes (2012, p. 44), de origem banta, mas de étimo ainda não exatamente determinado. Há o caracterize como originário do quimbundo bangue, mas apresenta algumas suposições: do nianja *bangwe, 'espécie de guitarra', do quimbundo *mbangala, 'bengala', do quicongo *mbúngu, 'cipó', do quicongo *mbánza, 'metade de um bambu', do quimbundo *mbangu, 'pá'.

Ver: pinguela, ponte, pau

-Acidentes geográficos.

\section{Cambumba s.f.}

CL 38 - ALiPE

Brincadeira em que se gira o corpo sobre a cabeça e acaba sentado.

N.L. Segundo encontrado em Lopes (2012, p. 69) o termo certamente tem origem banta, mas não apresenta sua etimologia.

Ver: cambalhota.

- Jogos e brincadeiras infantis.

\section{Capemba adj.}

CL 27 - ALiPE

Qualidade da pessoa que puxa de uma perna.

N.L. Proveniente de catenga, do quimbundo kaditende, 'lagartixa'. (LOPES, 2012 , p. 83). Ele também cita o termo * Katenga, do quimbundo, 'uma espécie de rato formigueiro de pelo grosso e fosforescente'.

Para Pereira da Costa (1957, p. 187), o termo constitui um regionalismo cearense para designar o invólucro do cacho da palmeira quando nova ou o pé da folha. Aqui parece ter semelhança analógica à capenga, por influência fonética. Esse termo advém do quimbundo, kiapenga, 'coxo'. Lopes (2012, p. 77), por sua vez, adverte para o fato de que, em línguas bantas, vocábulos contendo o núcleo 'eng' estão 
Carcará s.m.

CL 11 - ALiBUI

Mamífero que carrega os filhos numa bolsa que tem na barriga e solta um cheiro ruim quando se sente ameaçado.

N.L. Forma sincopada de caracará, do tupi

Ver: gambá, cangambá

- Fauna karaka'ra 'id.'

associados à ideia de manquejar, coxear. Isso é ratificado em Bernardino (2002, p. 62).

- Corpo humano.

Carucho s.m.

CL 20 - ALMASPE

Bichinho branco, enrugadinho, que dá em goiaba, em coco.

N.L. Variação desnasalizada de caruncho e de acordo com o Dicionário Etimológico, advém do latim carunclum, relacionado a caries, "apodrecimento, decomposição", ligado ao grego ker-, "morte, destruição".

Ver: tapuru, larva

-Fauna

\section{Catraia s.f.}

CL 33 - AliPE

Conhém adj.

CL 27 - ALMASPE, ALiPE

A mulher que se vende pra qualquer homem

N.L. Origem obscura

Ver bandoleira.

-Convívio e comportamento social.

\section{Corona s.f.}

CL 18 - AliPE

Objeto de couro com tampa para usar farinha no lombo do cavalo.

N.L.. Var. fon. coronha [ko'rõna]do espanhol antigo curueña, hoje cureña, 'peça que segura o cano de armas de fogo'. (FERREIRA, 1986, p. 481). Já 'corona' vem do latim corona, 'coroa'.

Ver alforje

- Atividades agropastoris.

Garajau s.m.

CL 14 - ALMASPE

Objetos de vime, de taquara, de cipós trançado(s) para levar batatas (mandioca, macaxeira, aipim, etc.), no lombo do cavalo ou do burro.

N.L. Origem controversa

Ver caçuá, balaio.

- Atividades agropastoris.

Jari s.m.

CL 16 - ALMASPE

Mamífero que carrega os filhos numa bolsa

que tem na barriga e solta um cheiro ruim
Aquele que puxa de uma perna

N.L. De origem desconhecida. Talvez advindo do latim congèner, 'de lado' ou uma alteração fonética de 'coxé', que significa 'coxo, manco'.

Ver capemba.

- Corpo humano.

Gambirra s.f.

CL 23 - ALiPE

N.L. Há duas hipóteses para o étimo de gambirra. Proveniente de gambá ou do italiano gamba, 'perna' + irra.

Ver cangambá

- Fauna.

Jacá s.m.

CL 14 - ALMASPE

Objetos de vime, de taquara, de cipós trançado(s) para levar batatas (mandioca, macaxeira, aipim, etc.), no lombo do cavalo ou do burro.

N.L. Do tupi aya'ka (HOUAISS, 2009)

Ver caçuá, balaio.

- Atividades agropastoris.

Mareta s.f.

CL 03 - ALiPE

Onda de rio

N.L. Do italiano maretta, pequena onda ou 
quando se sente ameaçado.

N.L. Redução de jaritataca, do tupi Ver: onda de rio, maré

*yagwara'taka ou *yarata'kaka < provavelmente oriundo de uma alteração do

tupi mbiara'taka (mbiarata'kaka)

influenciada pelo tupi ya'gwara (HOUAISS,

2009)

Ver: gambá, cangambá.

-Fauna

Misse s.m.

CL 43 - AliPE

Aquilo de metal que prende o cabelo

N.L. Do francês mise, prender. (CAUDAS

AULETE, s.d.)

Ver: grampo, biliro

- Comportamento e convívio social

Piola (ou biola) s.f.

CL 36 - AliPE

Ponta de cigarro que joga fora

V.L. Do espanhol platino piola, 'barbante, corda' (FERREIRA, 1986, p. 1333)

Ver baga, bituca, beata

-Convívio e comportamento social.

\section{Retruço s.m.}

CL 03 - ALiPE

Onda de rio

N.L. Não foi encontrada qualquer referência ao verbete nos dicionários de língua portuguesa, mas tudo leva a crer que o étimo partiu do latim retrudere 'empurrar para trás', influenciado por retruso.

Ver galão, onda de rio

-Acidentes geográficos. forma diminutiva de maré (maré + eta)

-Acidentes geográficos.
Náfego adj.

CL 27 - AliPE

Que puxa de uma perna

N.L. Para Ferreira (2004), o verbete vem de náfrego, alterado de náufrago, do latim naufragu, 'que afundou'.

Ver capemba

-Corpo humano.

Piúba s.f.

CL 36 - AliPE

Ponta de cigarro que joga fora

N.L. Não há registros étimos concretos, mas há suposições de que se trata de um item lexical de origem indígena.

Ver piola, baga, bituca, beata

-Convívio e comportamento social.

Saruê s.m

CL 13 - ALiBUI

Mamífero que solta um cheiro ruim quando ameaçado.

N.L. tupi sari'gwe, adaptado ao português como saruê (HOUAISS, 2009)

Ver. gambá, cangambá

-Fauna
Somítico adj.

CL 71 - ALiBUI

Aquele que não gosta de gastar dinheiro.

N.L. De semita+-ico (HOUAISS, 2009)

Ver. Avarento, velhaco

-Convívio e comportamento social.

\section{Trapiranga s.m.}

CL 95 - ALiBUI

Inflamação no olho que faz com que o olho amanheça grudado

N.L. Variante fonética de tapiranga, provavelmente corruptela de tiepiranga 'variedade de tiê, através da feminina

*tepiranga, com possível contaminação do 
Trunca(do) adj.

CL 11 - ALMASPE

Pessoa de pernas arqueadas

N.L. do latim truncátus, $a$, um (HOUAISS, 2009)

Ver: zambeta

-Corpo humano.

Ximbra s.f.

CL 39 - AliPE

Bolinhas de vidro com que os meninos gostam de brincar

Var. fon. ximbre [']î̉bri]

N.L. Não há uma referência etimológica comprovada a respeito. A despeito de suspeitas de o verbete ser apenas expressivo, Pereira da Costa (1957, p.752) fala de uma possível corruptela ou deturpação do vocábulo latino similis 'similar, igual' a partir do que apareceu no Diário de Pernambuco, no 12 de 1916 a seguinte manchete: "Estão hoje unidos. Separar-se-ão na escolha do Presidente da República, por cuja cadeira tanto um como outro dá a vida. Ximbre com ximbre; retalhos da mesma chita". $\mathrm{Na}$ opinião do autor, a expressão seria uma deturpação de similis cum similibus facile congregantur.

Ver bila, bola de gude, bolita

-Jogos e brincadeiras infantis. vocábulo tapir', a partir do tupi pirranga

'vermelho' (HOUAISS, 2009)

-Corpo humano

Vilídia s.f.

CL 23 - ALMASPE

Bolinha que nasce no olho, fica vermelha e incha.

N.L. Variante de belida. Os dicionários apontam origem controversa. O Priberam acredita na influência de velum.

- Corpo humano.

\section{CONCLUSÃO}

Trabalhar a Dialetologia e a Geolinguística agregada à Lexicografia ainda não é algo muito frequente, haja vista o número de artigos, monografias, dissertações e teses que estão registradas nas mesas dos pesquisadores Brasil a fora.

Assim, este artigo que amalgama os pressupostos teóricos da Lexicografia, sobretudo com relação à produção de glossários, e a Geolinguística, com destaque para as variantes lexicais encontradas nos atlas linguísticos, se torna um recurso a mais para documentar as marcas dialetais encontradas numa dada comunidade inquirida.

Aqui foram utilizados os corpora dos Atlas Linguísticos de Buíque, o primeiro municipal do Estado de Pernambuco, da Mata Sul, o pioneiro do gênero descritivo da língua falada no Estado, do Esboço de um atlas linguístico rural, cujos inquéritos ocorreram em seis sítios rurais e o Atlas Linguístico de Pernambuco, o trabalho mais recente que registrou variantes de 20 municípios que percorrem toda a sua extensão territorial. 
Fica, então, comprovada a importância de um trabalho dessa natureza por fazer o leitor entender um pouco mais do falar pernambucano, que, de maneira peculiar ou não, registra as marcas culturais do homem, de sua geração e as mantêm vivas na memória até se revelarem nos seus atos de fala.

\section{REFERÊNCIAS}

ALMEIDA, Edilene Oliveira. Atlas linguístico da mata sul de Pernambuco (ALMASPE). 2009. $151 \mathrm{f}$. Dissertação de Mestrado. Centro de Ciências Humanas, Letras e Arte, Universidade Federal da Paraíba, João Pessoa, 2009.

ALTINO, Fabiane Cristina Atlas linguístico do Paraná II (ALPR II). Tese de Doutorado. Universidade de Londrina, 2007.

ALVAR, Manuel. Atlas lingüísticos y diccionarios. LEA, IV. Madrid, 1982. p. 253-323.

ALVES, Ieda Maria; ISQUERDO, Aparecida Negri (orgs). As ciências do léxico. Campo Grande: UFMS, 2007.

ARAGÃO, Maria do Socorro Silva de; MENEZES, Cleuza Palmeira Bezerra de. Atlas linguístico da Paraíba. Brasília: Universidade Federal da Paraíba, 1984.

BARBOSA, Maria Aparecida. Da neologia à neologia na literatura. In: OLIVEIRA, Ana Maria P. Pires de; ISQUERDO, Aparecida Negri (Orgs.). As ciências do léxico: lexicologia, lexicografia, terminologia. 2. Campo Grande-MS: EDUFMS, 2001. v. 1.p. 33-51.

BERNARDINO, Bertrando. Minidicionário de Pernambuquês. 3. ed. Recife: Bagaço, 2002. BESSA, José Rogério F. et al. Atlas linguístico do Ceará. Fortaleza: UFC, 2010.

BIDERMAN, Maria Teresa Camargo. Teoria Lingüistica. São Paulo: Martins Fontes, 2001.

BORBA, Francisco da Silva. Organização de dicionários: uma introdução à Lexicografia. São Paulo: UNESP, 2003.

BOUTIN-QUESNEL, Rachel et al. Vocabulaire systématique de la terminologie. OLF, Québec, Publications du Québec, 1985.

CARVALHO, Nelly. Empréstimos linguísticos e identidade cultural. In ALVES, Ieda Maria et al (orgs.). Os estudos lexicais em diferentes perspectivas. São Paulo: FFLCH/USP, 2009.

CASARES, J. Introduccion a la lexicografia moderna. 3 ed. Madrid: Consejo Superior de Investigaciones Científicas, 1992.

CAUDAS AULETE, Dicionário Contemporâneo da Lingua Portuguesa. s.n.t.

FAULSTICH, Enilde. Socioterminologia: mais que um método de pesquisa, uma disciplina. Brasília, v.24, n. 3, p. 281-288, 1995.

FERREIRA, Aurélio Buarque de Holanda, Dicionário Aurélio, 4. ${ }^{a}$ ed., Curitiba: Melhoramentos, 1986.

FERrEIRA, C. e CARDOSO, S. A. M. A dialetologia no Brasil. São Paulo: Contexto, 1994.

FERREIRA, Joseane Cavalcanti. Atlas linguístico de Buíque (ALIBui). Monografia de especialização em Língua Portuguesa. UPE, Petrolina, 2010.

HAENSCH, $G$ et al. La lexicografia: de la lingüística teórica a la lexicografia práctica. Madrid: Gredos, 1982.

HOROZCO, Sebastián de Covarrubias. Tesoro de la lengua castellana o española. Madrid; Signatura: 1611.

HOUAISS, A. et al. Dicionário eletrônico Houaiss da língua portuguesa. Rio de Janeiro: Objetiva, 2009. 1 CD-ROM.

LOPES, N. Novo dicionário banto do Brasil, Rio de Janeiro: Pallas, 2012.

ISQUERDO, A. N. A propósito de dicionários de regionalismos do português do Brasil. In: ALVES, Ieda Maria (orgs.). As ciências do léxico: Lexicologia, Lexicografia e Terminologia. v. 3. Campo Grande, MS: Ed. UFMS; São Paulo: Humanitas, 2007, p. 193-208. 
OLIVEIRA, A. M. P. P.; ISQUERDO, A. N. (Orgs.) As ciências do léxico: Lexicologia, Lexicografia, Terminologia. v.1. Campo Grande-MS: Editora da UFMS, 2001.

Marcas dialetais num dicionário de língua. In: Estudos linguísticos. V. 28. São Paulo, 1999. p. 251-256.

OLIVEIRA, D. P. (Org.). Atlas Lingüístico de Mato Grosso do Sul. Campo Grande - MS: UFMS, 2007.

PEREIRA DA COSTA. Francisco Augusto. Vocabulário pernambucano. Governo do Estado de Pernambuco, Secretaria de Educação e Cultura, 1957.

RIBEIRO, José et al. Esboço de um atlas lingüístico de Minas Gerais. v. 1. Rio de Janeiro: Fundação Casa Rui Barbosa/ Universidade Federal de Juiz de Fora, 1977.

ROSSI, Nélson; FERREIRA, Carlota; ISENSEE, Dinah. Atlas prévio dos falares baianos. Rio de Janeiro: Instituto Nacional do Livro/Ministério da Educação e Cultura, 1963.

SÁ, Edmilson José de. Atlas linguístico de Pernambuco (ALiPE). 2013. 417 f. Tese de Doutorado. Centro de Ciências Humanas, Letras e Arte, Universidade Federal da Paraíba, João Pessoa, 2013. .; NETO, Austriclínio Andrade. Esboço de um atlas linguístico rural de Pernambuco: agreste centro-meridional de Pernambuco. Olinda: Livro Rápido, 2013.

SALVADOR, G. Lexicografía y geografía lingüistica. REL, 10,1 1980,p. 138-144.

SORIANO, J. García. Vocabulario del dialecto murciano. Murcia: Editora Regional, 1980, edición facsímil de la primera, Madrid, 1932.

VILELA, Mário. Estudos de lexicologia do português. Coimbra: Almedina, 1994.

ZANETTE, R. I.C. - A importância das notas em dicionário terminológico português/italiano. Revista TradTerm. Universidade de São Paulo. 18/2011.1, p.348-360.

ZUMBADO, Cristóbal José Corrales; DÍAZ, Dolores Corbella, "El ALEICan en los diccionarios", AFA, LIX-LX, 2002-2004, In: CASTAÑER, Rosa Maria; ENGUITA, José Maria (eds.) Archivo de filologia aragonesa. In memoriam de Manuel Alvar. p. 1203-1222.

Submetido em 24/07/2019

Aceito em 31/10/2019

Publicado em 14/02/2020 